\title{
Fighting Multiple Tax Havens
}

\author{
May Elsayyad \\ Kai A. Konrad
}

CESIFo Working PAPER No. 3195

CATEgory 1: Public FinANCE

SEPTEMBER 2010

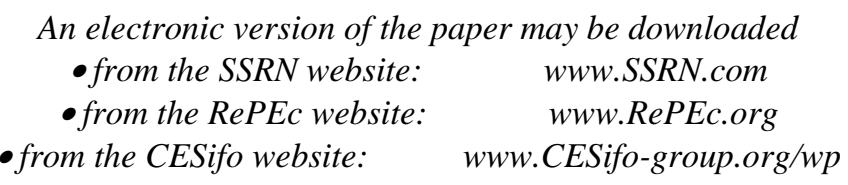




\title{
Fighting Multiple Tax Havens
}

\begin{abstract}
This paper develops a competition theory framework that evaluates an important aspect of the OECD's Harmful Tax Practices Initiative against tax havens. We show that the sequential nature of the process is harmful and more costly than a "big bang" multilateral agreement. The sequentiality may even prevent the process from being completed successfully. Closing down a subset of tax havens reduces competition among the havens that remain active. This makes their "tax haven business" more profitable and shifts a larger share of rents to these remaining tax havens, making them more reluctant to give up their "tax haven business". Moreover, the outcome of this process, reducing the number of tax havens, but not eliminating them altogether, may reduce welfare in the OECD.
\end{abstract}

JEL-Code: F21, H26, H77, H87.

Keywords: tax haven, harmful tax practices, bidding for haven inactivation.

May Elsayyad

Max Planck Institute for Intellectual

Property, Competition and Tax Law

Munich / Germany

May.Elsayyad@ip.mpg.de
Kai A. Konrad

Max Planck Institute for Intellectual

Property, Competition and Tax Law

Department of Public Economics

Marstallplatz 1

Germany - 80539 Munich

kai.konrad@ip.mpg.de

September 14, 2010

We thank Wolfgang Schön, Johannes Becker and Eckhard Janeba for valuable comments. The usual caveat applies. May Elsayyad gratefully acknowledges financial support from the German Science Foundation (DFG) through GRK 801. 


\section{Introduction}

The OECD report on Harmful Tax Competition (1998, p. 23) worked out a number of factors that may be used for identifying tax havens. One of these factors is existing national bank secrecy rules, which have been utilized to support tax haven activities. Such rules protect investors "against scrutiny by tax authorities, thereby prevening the effective exchange of information on taxpayers benefiting from the low tax jurisdiction" and effectively enable investors to avoid paying the respective capital income taxes in their country of residence. In response to this phenomenon, several initiatives have been launched against tax havens by the OECD, the G8, the United Nations Office for Drug Control and Crime Prevention and the European Union, since the 1990s.

Most prominent is the 1998 OECD initiative subsequently known as the Harmful Tax Practices Initiative, which was intended to discourage the use of preferential tax regimes for foreign investors and to encourage effective information exchange among the tax authorities of different countries. As part of the initiative, the OECD produced a list of countries and territories that it deemed to be tax havens. Starting out from this confrontational stance, over the years OECD attitudes with regards to tax havens shifted from confrontational to cooperative. OECD and non-OECD countries have worked together to develop mutual standards of transparency and exchange of information, which have come to serve as a model for a vast majority of the 3600 bilateral tax conventions entered into by the OECD and non-OECD countries and may now be considered as the international norm for tax cooperation. ${ }^{1}$ Many, but not all of the 1998 listed and identified havens have agreed over time to improve the transparency of their tax systems and to facilitate information exchange, and if this information exchange is sufficiently effective, this essentially would close down the respective country's activities as a tax haven. The dynamic process of implementation of these agreements, however, has been rather slow. ${ }^{2}$ Between 2000 and the London Summit Declaration in 2009, only 100 Tax Information Exchange Agreements (TIEAs)

\footnotetext{
${ }^{1}$ See Kudrle (2008)

${ }^{2}$ Furthermore, limited evidence does not suggest any impact of the OECD initiative on tax-haven activity. Kudrle (2008) examines total foreign portfolio investment in the Cayman Islands and in a broader set of tax-haven countries. His time-series analysis finds no significant impact of the OECD initiative. This supports the notion that the OECD initiative has not been implemented in practice to any meaningful extent.
} 
had been signed between OECD countries and the financial centers; furthermore, these signings for the most part have been limited to a small number of countries. Despite the surge in TIEA signings which has taken place in the months after the London Summit, it is evident that the fight against tax havens has followed a sequential pattern. ${ }^{3}$ Once general guidelines had been established, not all agreements were made simultaneously. Also they were not conditioned on each other. The agreements emerged as successive independent decisions, followed by a sequential implementation process.

Our analysis focuses on this aspect of sequentiality compared to a simultaneous approach, or rather a simultaneous coordinated approach of effectively closing down tax haven activity (i.e., by enforcing appropriate information exchange institutions that remove the implementation process). In particular, a tax haven's decision to comply with OECD rules and, effectively, give up its business as a tax shelter for residents in high-tax countries has implications for other tax havens' business opportunities and their incentives on whether to also comply with OECD rules. Tax havens, while providing capital concealment opportunities for mobile capital, also compete with each other for this capital. Now if the vast majority of competitors exits the tax haven business, this affects equilibrium behavior of both the residence countries of investors who use tax havens and of the tax haven business. This has implications for the equilibrium payoffs of residence countries and of the tax havens that remain active. Our analysis focuses on these market interactions, and the role of sequentiality of the fight against tax havens for welfare in the non-haven countries and for the market structure that is likely to emerge. We show that a sequential process of closing down the tax haven business of one tax haven country after the other is particularly costly, compared to a simultaneous, all-in-one approach. This is particularly true if the agenda setter who engages in the process of closing down tax havens were able to commit to a strategy of conditionality, linking the decisions of all tax havens. The OECD and other supranational entities engaged in the fight against tax havens may not have the option of an all-in-one approach. But for this case our analysis reveals a hidden cost of the sequential process that is not obvious from the outset. Furthermore, we show that given a sequential implementation pattern, from the perspective of the overall cost, it is less costly to approach larger havens first. A finding which does not correspond to the

\footnotetext{
${ }^{3}$ The initiative has remained concentrated on a small number of countries and the general characteristics of the signatories remain more or less unchanged.
} 
pattern of recent TIEA signings, which have mainly concentrated on smaller havens.

The public finance literature on tax havens has generated many insights into the role of tax havens and the functioning of tax competition in a world with tax havens. Despite the fact that the bulk of the tax haven literature has concentrated on the welfare implications of corporate tax planning and avoidance, a general consensus on the ramification of the existence of tax havens for corporations has not been reached. A widespread view argues that havens erode the tax base of high-tax countries and thus exacerbate the effects of tax competition. The positive view of tax havens, however, purports that tax havens enable high-tax countries to impose lower effective tax rates on highly mobile firms, while taxing immobile firms more heavily. The standard view underlying the OECD initiative is that tax havens may strengthen tax competition and erode the tax revenues of non-tax-haven countries. ${ }^{4}$ Some of the literature also reveals possible countervailing effects suggesting that tax havens may actually provide benefits as well. ${ }^{5}$ A diversity of views exists that is surveyed by Dharmapala (2008). However, this literature basically takes tax havens (typically one) as a given. ${ }^{6}$

Slemrod and Wilson (2009) while taking a negative view on tax havens and accounting for the existence of multiple tax havens and tax haven fighting expenditures, come to different conclusions as aspects of competition between tax havens, as well as specific anti-tax-haven initiatives are not specifically considered. To our knowledge the tax haven literature disregards the role of competition and market concentration between tax havens and the change in competition that emerges from the OECD policy that tries to change the set of tax havens. It is exactly this effect which needs to be taken into consideration in the process of closing down tax haven operations, however. The competition effect of forced exit in a framework with multiple, competing tax havens turns out to be most important for an assessment of the cost and benefits of the current OECD policy. ${ }^{7}$

\footnotetext{
${ }^{4} \mathrm{~A}$ formal analysis along these lines is provided by Slemrod and Wilson (2009). For an analysis focusing on the harmful effects for developing countries see, Torvik (2009).

${ }^{5}$ See, e.g., Hong and Smart (2010), Desai et al. (2006) and Johannesen (2010).

${ }^{6}$ Slemrod (2008) provides an empirical analysis of the possible factors (including income, literacy, development aid, size or whether a country is an island) that make it more or less likely that a country engages in activities as a tax haven (following the OECD classification).

${ }^{7}$ While considerable research has taken place to understand the economics of bilateral
} 
For a description of competition between tax havens we adopt the formal structure of Bertrand markets with subsets of price sensitive and loyal or uninformed consumers, building on the fundamental insights of Varian (1980). More specifically, for this competition between tax havens we rely on the competition model by Narasimhan (1988). ${ }^{8}$ This market structure is sufficiently general to map a whole continuum of competition regimes, ranging from local monopolies to cut-throat Bertrand competition, and it is suitable to consider the competition and market concentration effects stemming from policies that inactivate tax-haven activities of a subset of tax havens. The implications of these changes in market concentration for a simultaneous or sequential inactivation of tax havens are the main drivers of our results. Changes in market concentration play a major role in many other areas of international economics. Merger or exit by some competitors in a given market generates externalities to other competitors and also influences others' merger or exit decisions. ${ }^{9}$ These effects have been explored along a large variety of dimensions. Examples in contexts such as strategic trade policy, outsourcing, and other policy areas are Dixit (1984), Horn and Levinsohn (2001), Lommerud et al. (2006) and Norbäck et al. (2009). In our framework the change in market concentration is caused by one player who governs the possible exit or inactivation of some of his competitors and who anticipates that the induced exit of a competitor may change the opportunities and cost of inactivating further competitors.

Our paper is structured as follows: Section 2 develops the model framework. In sections 3 and 4 we solve for the equilibria of the multi-stage game. Section 5 compares the different results and their implications, and concludes.

versus multilateral trade agreements, see for example Bagwell and Staiger (2004), research involving bilateral tax treaties has mainly focused on their investment effects between high-tax countries, see Chisik and Davies (2004).

${ }^{8}$ This competition model is extended in multiple directions in Industrial Organization and has become a "workhorse model", similar to the standard Cournot or Bertrand framework, and many competition modes are nested in this framework. In the field of public finance, the modifications of this competition model have been used by Wang (2004), Andersson and Konrad (2001), Konrad and Kovenock (2009) and Marceau et al. (2010).

${ }^{9}$ The externalities of merger often make it more attractive to be an outsider than to participate in a merger, which leads to the question of endogenous merger. See Horn and Persson (2001) for a discussion and a possible approach. In our framework this endogeneity is not an issue as a strong player governs the process of tax haven inactivation here. 


\section{The structure of the problem}

We consider a game with three players: One player is the government in the country that engages in fighting tax havens (or, for that purpose, the OECD). We call this player $S$. Residents in $S$ are the sole owners of financial capital. The other two players are tax havens, denoted $H_{1}$ and $H_{2}$, which seek to attract mobile capital by offering concealment services. Depending on the tax rate on capital income in $S$, whether the tax havens are active, and the terms which the tax havens offer for their services, financial capital can allocate between $S, H_{1}$ and $H_{2}$.

We consider the following multi-stage game:

In Phase 1 - the haven deactivation phase - actions by $S, H_{1}$ and $H_{2}$ determine whether no, one or two tax havens will be available for investors. In intuitive terms, in this phase the government of $S$ may buy out one or both tax havens. This means, country $S$ may offer to compensate the tax haven in exchange for its promise to discontinue its tax haven business meaning that they fully cooperate with $S$ regarding information exchange. This essentially allows for the full implementation of the residence principle on capital income, and leads to a situation in which $H_{1}, H_{2}$ or both would become useless as havens. The assumption by which $S$ compensates the tax havens to terminate their operation rather than threatening them with retaliatory actions that are costly for the country that carries them out is mainly for analytical simplicity and clarity. ${ }^{10}$

We distinguish between two different types of offers made. One of these regimes is seen as a possible option that is currently not pursued. The other regime maps more closely the current OECD initiative.

Simultaneous joint offer: Country $S$ may offer payments $b_{1} \geq 0$ and $b_{2} \geq 0$ to the two tax havens $H_{1}$ and $H_{2}$, respectively. $S$ is able to commit to either pay both amounts or none, and to make this payment dependent on whether both havens agree. Tax havens then simultaneously and independently declare whether they would be willing to accept this offer. This declaration requires some ability to commit. Each tax haven commits to close down in exchange for receiving the payment, but continues to operate if no payment is received. Accordingly, if both agree, then $S$ makes both

\footnotetext{
${ }^{10} \mathrm{It}$ is clear that any punishment threat is costly for $S$ as well, and that it causes a differential in payoff for the tax haven between being punished and not beeing punished. Unlike a simple compensation that we consider, the cost and this differential need not be of equal size.
} 
payments. If payments are made, both tax havens go out of business. If only one tax haven declares agreement or if none of the tax havens declares agreement, then no money is paid out and both tax havens remain active, and we move to Phase 2 of the game with two active tax havens.

Sequential offers: Country $S$ may first offer a payment $b_{i}$ to one of the tax havens $H_{i}$. This tax haven has to decide whether to accept this offer and to become inactive in phase 2 , or to remain active. Based on this outcome country $S$ may offer a payment $b_{-i}$ to the other tax haven, $H_{-i}$. The choice of making this offer, and the payment chosen, typically will depend on the outcome of the first offer made, and on whether it has been accepted or not. Also, whether the tax haven $H_{-i}$ accepts or rejects this offer can generally be dependent on the first offer made and whether it has been accepted or not.

We assume that the havens accept the offer if they are indifferent between accepting or rejecting. This ends Phase 1.

At the beginning of Phase 2 -the competition phase- the set of active tax havens is either $\left\{H_{1}, H_{2}\right\},\left\{H_{1}\right\},\left\{H_{2}\right\}$ or $\varnothing$. $S$ first chooses a tax rate $t$ that applies to financial capital invested in country $S$. This tax rate is from a closed interval $[0, r]$. The upper end of this interval is exogenously given and reflects institutional or political conditions in country $S$. This tax has to be paid by each unit of financial capital that will locate in $S$. Tax havens that are active (that is, tax havens that have not accepted or received an offer by $S$ in Phase 1) can then choose proportional user fees $p_{1} \in[0, r]$ and $p_{2} \in[0, r]$ that also apply to each unit of financial capital that will be invested in the respective tax haven. In exchange for the fee they guarantee the investor full secrecy as regards his or her capital income. ${ }^{11}$ We assume that investors can fully rely on this promise. Hence, investors save the residence income tax $t$ on this capital income.

Once the conditions for investment are known, the financial capital is allocated between $S, H_{1}$ and $H_{2}$ as a function of the tax $t$ and, if the respective tax haven is active, the user fees $p_{i}$ for $i \in\{1,2\}$ in the active tax havens. We do not explicitly model the investors as players. The total amount of

\footnotetext{
${ }^{11}$ Typically, these fees are paid to the financial service industry that operates in the tax haven, rather than to the government of the tax haven directly. If the financial market inside a tax haven is a competitive market, however, these fees are essentially determined by licence fees and charges which the tax haven collects from the local firms or local branches operating in this sector. A more disaggregated framework with a competitive financial services sector in each tax haven would require further notation and yields analogous results.
} 
financial capital is normalized to 1 , and is owned by residents of country $S$. There are three different types of financial capital. A share $s$ of this financial capital is immobile. This is the share of capital owned by residents who cannot, or would never like to invest their financial capital offshore and simply pay whatever is the tax rate in country $S$. Shares $h_{i}$ of capital are mobile only between $S$ and one of the respective tax haven $H_{i}$ for $i \in\{1,2\}$. The share $h_{i}$ of financial capital is invested in $H_{i}$ if and only if $p_{i} \leq t .{ }^{12}$ This assumption corresponds to the notion that some investors may have an affinity for particular tax haven countries. This affinity could, for instance, be based on geographical proximity, language, a convenient legal code etc. Finally, there is a remaining amount of financial capital that is perfectly mobile. This amount is denoted by $\beta=1-s-h_{1}-h_{2}$. $\beta$ stays in $S$ if $t$ is smaller than $p_{i}$ for all tax havens that are active. It moves to a tax haven rather than staying in $S$ if the user fee in one of the active tax havens is at least as low as the tax. If both tax havens are active and the user fees in both tax havens are not higher than $t$, this capital locates to the tax haven with the lower user fee, and if both tax havens are active and $p_{1}=p_{2} \leq t$, equal shares of this fully mobile capital locate to each of the two tax havens. ${ }^{13}$

Capital yields the same gross return, independent of where it is located (which is a natural assumption in case of a well integrated international capital market). And it does not restrict generality if we normalize this return to zero, i.e., assume that one unit of financial investment turns into one unit of gross financial return, and -as is common in the tax competition literature- consider taxes and fees on capital, rather than on its returns.

Finally, we need to specify the payoffs of $S, H_{1}$ and $H_{2}$. Each tax haven maximizes the sum of user fees $p_{i}$ and payments $b_{i}$ received from $S$. An active tax haven does not receive any payment from $S$ and its payoff equals its user fees, which is equal to the product of $p_{i}$ and the amount of financial capital $x_{i}$ that is invested in this tax haven, where the $x_{i}$ 's are generally functions of $t$ and $p_{i}$, and of whether the other tax haven is active. This is considered in more detail further below.

The payoff of country $S$ is less straightforward. The benevolent govern-

\footnotetext{
${ }^{12}$ For $p_{i}=t$ this is the natural tie-breaking assumption, given that $S$ chooses $t$ prior to the tax havens' choices of fees.

${ }^{13}$ Note that the capital owners are not strategic players here. They simply invest their capital where the cost of investment is smallest for them. This avoids measurability problems of dealing with a continuum of players and is essentially a technical simplification of the problem.
} 
ment in country $S$ maximizes

$$
\begin{aligned}
\pi_{S}= & (1-t)\left(1-x_{1}-x_{2}\right)+\left(1-p_{1}\right) x_{1}+\left(1-p_{2}\right) x_{2} \\
& +(1+\lambda) t\left(1-x_{1}-x_{2}\right)-(1+\lambda)\left(\theta_{1} b_{1}+\theta_{2} b_{2}\right)
\end{aligned}
$$

This payoff consists of several terms. The first term in (1) is the net-of-tax return on domestically invested capital. The second and third term represent the capital incomes of residents net of user fees $p_{1} x_{1}$ and $p_{2} x_{2}$ paid on the amounts $x_{1}$ and $x_{2}$ that result from the financial assets shifted offshore to the two tax havens $H_{1}$ and $H_{2}$. The fourth term is the social valuation of the capital tax revenue. This is equal to the product of $(1+\lambda)$ and the tax revenue. The tax revenue is equal to $t$ times the amount of financial capital that locates to $S$. The factor $(1+\lambda)$ accounts for the fact that government revenue has a shadow price $(1+\lambda)$ that exceeds unity by $\lambda>0$, due to the excess burden of taxation from other revenue sources. The last term is the social cost of possible payments $b_{1}$ and $b_{2}$ that are offered to the tax havens. These depend on whether the tax havens accept these payments (for becoming inactive). Here, $\theta_{1}$ and $\theta_{1}$ are indicator variables that are equal to 1 and 0 , depending on whether or not the payments are accepted and made. We will assume that this payoff function applies for $S$.

To solve the different variants of this game we use the concept of subgame perfect equilibrium. We start with solving for the set of equilibria in phase 2 for different combinations of active tax havens.

\section{Equilibrium in Phase 2}

If both tax havens are active Country $S$ chooses $t$ prior to the tax havens' choices of $p_{1}$ and $p_{2}$. Consider the payoff of $H_{i}$ for a given $t$ and $p_{j}$ :

$$
\pi_{H_{i}}=p_{i} x_{i}= \begin{cases}0 & \text { if } p_{i}>t \\ p_{i} h_{i}+p_{i} \beta & \text { if } p_{i}<p_{-i} \leq t \\ p_{i} h_{i}+\frac{1}{2} p_{i} \beta & \text { if } p_{i}=p_{-i} \leq t \\ p_{i} h_{i} & \text { if } t \geq p_{i}>p_{-i}\end{cases}
$$

for $i,-i \in\{1,2\}$. A choice of $p_{i}>t$ will render the haven zero profits. For $p_{i} \leq t$, if $H_{i}$ offers lower user fees $p_{i}$ than its haven competitor, it attracts its partially mobile capital segment $h_{i}$ and the price sensitive segment $\beta$. If it offers its services for a fee $p_{i}$ that is higher than its haven competitor, then 
it attracts only its partially mobile capital segment. If the two havens set the same level of user fees, then each gets its partially mobile segment, while the price sensitive $\beta$ segment is equally divided between the two havens.

A few considerations limit the range of possible equilibrium choices of fees in the tax havens. First, by (2) tax havens will never choose $p_{i}>t$ for $t>0$. A price $p_{i}>t$ implies zero payoff, and setting any other price level lower than or equal to $t$ would ensure higher haven profits than 0 . Also, while competing for the price sensitive mobile segment $\beta$, havens will never set a price which is lower than

$$
\hat{p}_{i}=\frac{t h_{i}}{h_{i}+\beta}
$$

The reason for this is as follows. The haven $H_{i}$ has a "default" option: by setting $p_{i}=t$ tax haven $H_{i}$ can obtain a profit which cannot fall below $t h_{i}$, irrespective of the other tax haven's choice. The maximum payoff obtainable from a $p_{i}<t$ is $p_{i}\left(h_{i}+\beta\right)$ and this maximum is obtained if, choosing this fee, the haven succeeds in capturing the whole price-sensitive mobile segment $\beta$. Note that, by $h_{1}>h_{2}$, it follows that $\hat{p}_{1}>\hat{p}_{2}$. But given that $p_{1} \geq \hat{p}_{1}$, $H_{2}$ does not choose $p_{2}<\hat{p}_{1}$, as such a price is dominated by a price closer to $\hat{p}_{1}$. This narrows down the range of possible fees chosen in an equilibrium to the interval $\left[\hat{p}_{1}, t\right]$. Note further that, for any given $t \in(0, r]$, there is no Nash equilibrium in pure strategies. ${ }^{14}$ Intuitively, haven $H_{i}$ has an incentive to undercut haven $H_{-i}$ 's user fee by a very small amount in regions in which prices are above the floor $\hat{p}_{1}$, as this lures the whole mobile segment $\beta$ to $H_{i}$. And $p_{1}=p_{2}=\hat{p}_{1}$ is also not an equilibrium, as, from there, deviations towards $p_{i}=t$ pay for at least one player.

The competition between tax havens for a given $t$ is structurally equivalent to Bertrand competition between two firms with loyal customers as in Narasimhan (1988), and we can use his results on existence and uniqueness of an equilibrium and its characterization. A unique equilibrium exists and lies in mixed strategies. In this equilibrium each haven picks its price inde-

\footnotetext{
${ }^{14}$ To confirm this, suppose that $\left(p_{1}^{*}, p_{2}^{*}\right) \in\left[\hat{p}_{1}, r\right] \times\left[\hat{p}_{1}, r\right]$ is such an equilibrium. Note that $p_{1}^{*}$ and $p_{2}^{*}$ cannot be mutually optimal replies if $p_{1}^{*}>\hat{p}_{1}$ and $p_{2}^{*}>\hat{p}_{1}$. Suppose they are, and let $p_{i}^{*} \leq p_{-i}^{*}$. Then $-i$ could increase its payoff by moving to $p_{i}^{*}-\epsilon$ for sufficiently small but positive $\epsilon$. Note next that $p_{1}^{*}$ and $p_{2}^{*}$ cannot be mutually optimal replies if $\min \left\{p_{1}^{*}, p_{2}^{*}\right\}=\hat{p}_{1}$. Two cases need to be distinguished. If $p_{1}^{*}=p_{2}^{*}=\hat{p}_{1}$ then Haven 1 can do better by choosing $p_{1}=r$. If $p_{i}^{*}>p_{-i}^{*}=\hat{p}_{1}$, then $-i$ can do better by increasing its price by half the difference between $p_{i}^{*}$ and $p_{-i}^{*}$. This shows that the claim of existence of a pure strategy equilibrium leads to a contradiction.
} 
pendently and randomly according to a cumulative distribution function $F_{i}$ for $i=(1,2)$ with support $\left[\hat{p}_{1}, t\right]$, with haven $H_{1}$ having a mass point at $t$. The following lemma describes the havens' payoffs in this equilibrium.

Lemma 1 (Narasimhan (1988)) For $t>0$ there exists a unique equilibrium of the subgame between two active havens. ${ }^{15}$ The equilibrium is in mixed strategies with expected payoffs

$$
E\left(\pi_{1}\right)=h_{1} t \text { for } H_{1} \text { and } E\left(\pi_{2}\right)=\frac{h_{1} t}{h_{1}+\beta}\left(h_{2}+\beta\right) \text { for } H_{2} .
$$

A feature of the equilibrium in the competition between tax havens is that the haven $H_{1}$ with the larger partially mobile segment earns the same profit in equilibrium that it would earn if it were to set $p_{1}=t$ with probability 1 , whereas the haven $H_{2}$ with the smaller $h_{i}$ segment earns $h_{1} t\left(h_{2}+\beta\right) /\left(h_{1}+\beta\right)$, which is higher than the profit $h_{2} t$ that $H_{2}$ could make if it focused on its partially mobile segment. Hence, this tax haven's profit is positive even if it has no own partially mobile capital segment, i.e., for $h_{2}=0$.

The competition framework used here has several advantages. First, it is sufficiently general to have many standard cases as special cases. Suppose, for instance, that $h_{1}=h_{2} \equiv h$. Then the equilibrium is symmetric. Both tax havens would earn the same payoff $t h$. For $h=0$ this payoff becomes equal to zero, as this is the case of Bertrand competition for a perfectly homogenous product and without loyal customers. Also, if the fully price-sensitive share $\beta$ converges towards zero, then both tax havens simply charge the monopoly price as the pure equilibrium strategy. Second, the framework has the advantage of providing uniquely determined payoffs in the competition subgame. Narasimhan (1988) proves the uniqueness of the equilibrium. This allows us to consider a contracted game in which we can replace the subgame by the unique equilibrium payoffs of this last stage.

Using the results from Lemma 1, we can also calculate the payoff of country $S$ as a function of $t$, assuming subgame perfect equilibrium play among the tax havens. The payoff of $S$ is

$$
1-s t-h_{1} t-\frac{h_{1} t}{h_{1}+\beta}\left(h_{2}+\beta\right)+(1+\lambda) t s
$$

\footnotetext{
${ }^{15}$ For completeness we report the cumulative distribution functions characterizing the equilibrium. These are $F_{1}(p)=F_{2}(p)=0$ for $p<h_{1} t /\left(h_{1} t+\beta\right), F_{1}=1+\frac{h_{2}}{\beta}-\frac{h_{1} t\left(h_{2}+\beta\right)}{\beta p\left(h_{1}+\beta\right)}$ and $F_{2}=1-\frac{h_{1}(t-p)}{\beta p}$ for $\frac{h_{1} t}{h_{1} t+\beta} \leq p \leq t$ and $F_{1}=F_{2}=1$ for $p>t$.
} 
Note that, for any $t>0$, one or both of the tax havens attract the mobile tax base. Hence, welfare of the country consists of investors' expected net returns plus $(1+\lambda)$ times the tax revenue, minus $(1+\lambda)$ times the payments for closing down tax havens (zero in this case, as both tax havens are active compared to (1)). The immobile capital (quantity $s$ ) stays in country $S$. All other capital is invested in the equilibrium in one or the other tax haven for $t \in(0, r]$. The expected fees collected by the tax havens are equal to their expected payoffs, and are generally a function of $t$. The investors' returns from investing in the tax havens is reduced by these expected payoffs.

Country $S$ maximizes (5) with respect to $t$. This yields the following result.

Proposition 1 (i) Let $\lambda>\left[1+\frac{h_{2}+\beta}{h_{1}+\beta}\right]\left(h_{1} / s\right)$. In the subgame perfect equilibrium of the continuation game with two active tax havens, $S$ chooses $t=r$. The expected equilibrium profits of the tax havens and of $S$ are:

$$
\begin{gathered}
E\left(\pi_{1}\right)=h_{1} r \text { and } \\
E\left(\pi_{2}\right)=\left[h_{2}+\beta\right] \frac{h_{1} r}{h_{1}+\beta} \text { and } \\
E\left(\pi_{S}\right)=1+\lambda r s-h_{1} r-\frac{h_{1} r}{h_{1}+\beta}\left(h_{2}+\beta\right)
\end{gathered}
$$

(ii) Let $\lambda<\left[1+\frac{h_{2}+\beta}{h_{1}+\beta}\right]\left(h_{1} / s\right)$. Then the subgame perfect equilibrium of the continuation game with two active tax havens is described by $t=0, E\left(\pi_{1}\right)=$ $E\left(\pi_{2}\right)=0$ and $E\left(\pi_{S}\right)=1$.

Proof. Consider $S$ 's optimal choice $t$ from the interval $[0, r]$ of feasible tax rates, anticipating equilibrium play in the continuation game for any given choice of $t$. The country's objective is to maximize

$$
1+\lambda t s-h_{1} t-\frac{h_{1} t}{h_{1}+\beta}\left(h_{2}+\beta\right)
$$

The gradient of the expression in (7) with respect to $t$ is

$$
\frac{\partial E\left(\pi_{s}\right)}{\partial t}=\lambda s-h_{1}-\frac{h_{1}}{h_{1}+\beta}\left(h_{2}+\beta\right),
$$

and is independent of $t$. The gradient is positive if $\lambda>\left[1+\frac{h_{2}+\beta}{h_{1}+\beta}\right] \frac{h_{1}}{s}$. The payoff of $S$ is maximal for the maximum feasible $t$, which is $t=r$. The equilibrium payoffs in (6) follow from $t=r$, Lemma 1 and from inserting $t=r$ into the payoff function (5) for $S$. 
The gradient in (7) is independent of $t$ and negative if $\lambda<\left[1+\frac{h_{2}+\beta}{h_{1}+\beta}\right] \frac{h_{1}}{s}$. For $\lambda$ smaller than this threshold, the optimal choice of the tax rate is, therefore, the smallest possible tax rate, $t=0$. In this case any possible choice of $p_{1}$ and $p_{2}$ yields the same payoffs (of zero) for both tax havens, and $\pi_{S}=1$ by (5). Note also that there is a multiplicity of equilibria for $t=0$, as all $p_{i}$ and $p_{j}$ lead to the same payoffs. The (unique) equilibrium for $t>0$ converges towards the equilibrium with $p_{1}=p_{2}=0$ for $t=0$ at the limit. But in any case, all the equilibria have the same payoffs for all players.

Intuitively, given that the two tax havens choose their fees $p_{1}$ and $p_{2}$ for hosting capital after $t$ is chosen, they will always attract all of the pricesensitive mobile capital. As $S$ takes these equilibrium choices of the two active tax havens into account, only the immobile capital remains in $S$, regardless of the choice of $t$. This means that the tax base in $S$ at equilibrium remains unaffected by changes in $p_{1}$ and $p_{2}$. Consequently, it is the shadow price of public funds, $\lambda$, which determines whether the government is willing to set the tax rate equal to 0 or to the maximum rate. The threshold value is

$$
\hat{\lambda}=\left[1+\frac{h_{2}+\beta}{h_{1}+\beta}\right]\left(h_{1} / s\right) .
$$

This threshold value $\hat{\lambda}$ depends on the mobility composition of the financial capital. In particular,

$$
\begin{gathered}
\frac{\partial \hat{\lambda}}{\partial h_{1}}=\frac{1}{s\left(\beta+h_{1}\right)^{2}}\left(2 \beta^{2}+2 \beta h_{1}+h_{2} \beta+h_{1}^{2}\right)>0 \\
\frac{\partial \hat{\lambda}}{\partial h_{2}}=\frac{1}{s} \frac{h_{1}}{\beta+h_{1}}>0 \\
\frac{\partial \hat{\lambda}}{\partial \beta}=\frac{1}{s} h_{1} \frac{h_{1}-h_{2}}{\left(\beta+h_{1}\right)^{2}}>0, \text { given that } h_{1}>h_{2}
\end{gathered}
$$

and

$$
\frac{\partial \hat{\lambda}}{\partial s}=-\frac{1}{s^{2}} \frac{h_{1}}{\beta+h_{1}}\left(2 \beta+h_{1}+h_{2}\right)<0,
$$

i.e., an increase in any of the mobile capital segments results in an increase in $\hat{\lambda}$, while an increase in $s$ decreases the size of the critical shadow price of public funds. Of course, none of $h_{1}, h_{2}, \beta$ or $s$ can change in isolation, as they are connected through the budget constraint. However, the differential incidence can be calculated from the results (10) to (13) on partial incidence. 
If only one tax haven $H_{i}$ is active Suppose only one tax haven $H_{i}$ is active. This changes the possible options for financial capital. For the capital $h_{i}$ that either locates to the active tax haven $H_{i}$ or to $S$, and for the immobile capital segment $s$ the investment options do not change. The price-sensitive capital segment $\beta$ can now locate only in two locations, $S$ or $H_{i}$. The capital share $h_{j}$ that was mobile only between $S$ and the now inactive $H_{j}$ becomes immobile: As $H_{j}$ is no longer active, $h_{j}$ remains in $S$.

As $H_{j}$ but not $H_{i}$ is deactivated, a payment $b_{j}$ has been made, and no payment has been made to $H_{i}$. Hence, $\theta_{j}=1$ and $\theta_{i}=0$ hold. Note that, in the following section, the newly added superscripts to the payoff function refer to the haven which has been deactivated. To differentiate between the possible regimes, we use the following notation for the payoff of $S: \pi_{S}^{k}$ denotes the payoff of $S$ as a function of the regime, where superscript $k=0$ refers to the default state regime (both tax havens active), $k=1, k=2$ and $k=1,2$ refer to the regimes with $i=1$ or $i=2$ or $i=1$ and $i=2$ deactivated.

Proposition 2 Suppose that $H_{j}$ has been deactivated due to a payment $b_{j}$. (i) If $\lambda>\left(h_{i}+\beta\right) /\left(s+h_{j}\right)$ then the subgame perfect equilibrium in Phase 2 is unique in payoffs and characterized by $p_{i}=t=r$ with payoffs:

$$
\begin{gathered}
\pi_{i}^{j}=\left(h_{i}+\beta\right) r \\
\pi_{j}^{j}=b_{j} \text { and } \\
\pi_{S}^{j}=1+\left(s+h_{j}\right) \lambda r-\left(h_{i}+\beta\right) r-(1+\lambda) b_{j} .
\end{gathered}
$$

(ii) If $\lambda<\left(h_{i}+\beta\right) /\left(s+h_{j}\right)$ then the subgame perfect equilibrium in Phase 2 is unique and characterized by $p_{i}=t=0$, with payoffs $\pi_{S}^{j}=1-(1+\lambda) b_{j}$, $\pi_{i}=0$ and $\pi_{j}^{j}=b_{j}$.

(iii) For $\lambda=\left(h_{i}+\beta\right) /\left(s+h_{j}\right)$ both equilibria exist.

Proof. Using backward induction, consider the last stage. The only active tax haven $H_{i}$ chooses $p_{i}$ for given $t \in[0, r]$ to maximize $H_{i}$ 's payoff $p_{i} x_{i}$, with $x_{i}=0$ if $p_{i}>t$ and $x_{i}=1-s-h_{j}$ if $p_{i} \in[0, t]$. The solution of this maximization problem is $p_{i}=t$ for all $t \geq 0$ and yields a payoff of $\left(1-s-h_{j}\right) t=\left(\beta+h_{i}\right) t$. For $t>0$, the optimal $p_{i}$ is unique. For $t=0$, all possible $p_{i}$ yield the same payoff of zero. Turn next to the optimal choice of $t$ and take into consideration that at this stage $b_{j}$ is exogenously given and that $p_{i}=t$ in the continuation game for $t>0$. Country $S$ maximizes

$$
1-\left(s+h_{j}\right) t-\left(h_{i}+\beta\right) t+(1+\lambda)\left(\left(s+h_{j}\right) t-b_{j}\right)
$$


The gradient of this payoff with respect to $t$ is $-\left(s+h_{j}\right)-\left(h_{i}+\beta\right)+(1+$ $\lambda)\left(s+h_{j}\right)$ and independent of $t$. Accordingly, the optimal choice is a corner solution. $S$ chooses $t=r$ (i.e., the largest feasible tax rate) if $\left(s+h_{j}\right) \lambda>h_{i}+\beta$ and $t=0$ if $\left(s+h_{j}\right) \lambda<h_{i}+\beta$, which reduces to the condition for $\lambda$ in the proposition. Finally, for $\left(s+h_{j}\right) \lambda=h_{i}+\beta$ both $t=r$ (with the respective equilibrium of the subgame as in (i)) and $t=r$ (with the respective equilibrium as in (ii)) yield the same payoff for $S$ and this payoff is higher than from any choice $t \in(0, r)$.

Intuitively, given the sequential structure of the tax decision, the mobile capital will always leave $S$ for any $t>0$, and for $t=0$, whether the capital locates to $S$ or $H_{1}$ (with $p_{1}=0$ ) is payoff-irrelevant. Due to the lack of competition for the mobile capital segment, the active tax haven earns the monopoly profit from the entire share of financial capital that is mobile between $S$ and $H_{i}$. It chooses $p_{i}=t$ as this ensures maximum profit for the tax haven $H_{i}$ which is active. With $S$ 's choice of $t$ not affecting the final destination of the mobile capital segment, $S$ chooses $t=r$ only if $\lambda$ is sufficiently high. The condition for $\lambda$ to be sufficiently high is also intuitive. A high tax is more beneficial for the country if its equilibrium tax base is large (i.e., $s+h_{j}$ is large), and if $\left(h_{i}+\beta\right)$, which is the base on which the country as a whole loses the fees to the tax haven, is small.

If none of the tax havens is active Suppose $S$ has deactivated both havens and financial capital can only remain in $S$. Accordingly, all capital remains in country $S$, the country has to pay $b_{1}$ and $b_{2}$, and can charge any tax rate $t \in[0, r]$. The payoff function of $S$ becomes

$$
1-t+(1+\lambda)\left(t-b_{1}-b_{2}\right)
$$

and this payoff reaches a maximum equal to $1+\lambda r-(1+\lambda)\left(b_{1}+b_{2}\right)$ for $t=r$.

Proposition 3 If both tax havens are deactivated, then $S$ chooses $t=r$ and has a payoff $\pi_{s}^{1,2}=1+\lambda r-(1+\lambda)\left(b_{1}+b_{2}\right)$. The payoffs of the tax havens are $\pi_{1}^{1,2}=b_{1}$ and $\pi_{2}^{1,2}=b_{2}$. 


\section{Equilibrium in Phase 1}

In what follows we focus on the case in which the shadow price of public funds is sufficiently high to make a high-tax strategy always preferable for $S$. We first show that $S$ cannot expect to gain from deactivating just one tax haven, assuming equilibrium play in Phase 2. We then consider the cost and benefit of deactivating both tax havens for the sequential regime and the regime with simultaneous joint offers. This comparison leads to our main results: An equilibrium with simultaneous joint offers exists, whereas sequential offers are never profitable for $S$.

\subsection{Deactivation of only one tax haven}

Consider first the deactivation of one tax haven compared to both tax havens being active. Deactivation yields an increase in profits for the active tax haven for any given $t>0$. The remaining haven faces no further competition from other tax havens. If only $H_{1}$ remains active, an optimal reply for any given $t \in(0, r]$ is $p_{1}=t$, which yields a payoff of $\left(h_{1}+\beta\right) t$, rather than the payoff $h_{1} t$ in the default state. Hence, the profit increase is larger if the fully mobile share of capital is larger. If only $\mathrm{H}_{2}$ remains active, its payoff

increases from $\left[h_{2}+\beta\right] t \frac{h_{1}}{h_{1}+\beta}$ to $\left(h_{2}+\beta\right) t$. This increase is also higher for a higher $\beta$, but lower for a smaller $h_{1}$. Intuitively, a larger $h_{1}$ makes haven $H_{1}$ less aggressive in the competition. Hence, there is less to gain for $H_{2}$ from removing its competitor $H_{1}$ if $h_{1}$ is larger. Note also that monopoly profits for a tax haven need not be larger than the aggregate profits in the case where both havens are active. Deactivation of a tax haven $H_{i}$ shifts the share $h_{i}$ of capital away from the tax havens, which is a payoff-reducing effect. However, removal of competition between tax havens also increases equilibrium user fees in the remaining tax haven, which increases the payoff of the active haven.

For $S$, deactivating one tax haven has several effects. We analyze these along the lines of effects on net capital income of residents and on net tax revenue. If only one active tax haven remains, the level of gross capital remaining in $S$ increases by the newly deactivated segment. Immobile capital is always taxed at the rate $r$. Second, there is a reduction in investors' rents. This is due to higher user fees that are charged on the mobile capital if only one tax haven is active, compared to a situation with several competing tax havens. Hence, with only one tax haven active, all capital (inside and outside 
$S$ ) is charged at the same rate $r$. Third, compared to both tax havens being active, deactivation increases the tax revenue flowing to $S$. However, the country has to pay for the deactivation of one tax haven, which contributes to a reduction of the payoff of country $S$.

We first confirm that the deactivation of only one tax haven is dominated by other choices for country $S$, and then turn to the comparison of payoffs from deactivation of both tax havens versus the payoffs in the default state. We state this claim as a proposition.

Proposition 4 Country $S$ has a higher payoff if both tax havens are active than if it deactivates only one haven.

Proof. Note that the effects of the deactivation on the payoff of $S$ differ for the two havens if $h_{1} \neq h_{2}$, as both the level of capital that is rendered immobile and the compensation needed for a successful deactivation are not the same for both tax havens. Note further that both regimes in the deactivation phase coincide if $S$ makes an offer to only one tax haven.

Country $S$ has a higher payoff from deactivating one and only one haven $H_{i}$ for a compensation of $b_{i}$ compared to the default state if $\pi_{S}^{i} \geq \pi_{S}^{0}$. This can be rewritten

$$
\begin{aligned}
\pi_{S}^{i} & =\underbrace{(1-r)\left(s+h_{i}\right)+\left(h_{-i}+\beta\right)-\underbrace{r\left(h_{-i}+\beta\right)}_{\text {active haven's profits }}}_{\text {net capital income }}+(1+\lambda) \underbrace{\left.r\left(s+h_{i}\right)-b_{i}\right]}_{\text {net tax revenue }} \\
& \geqslant \underbrace{1-r s-\underbrace{\left(h_{1} r+\frac{h_{1}}{\left(h_{1}+\beta\right)} r\left(h_{2}+\beta\right)\right)}_{\text {aggregate haven's profits }}+(1+\lambda) \underbrace{r(s)}_{\begin{array}{c}
r s \\
\text { net tax revenue }
\end{array}}}_{\text {net capital income }}=\pi_{S}^{0}
\end{aligned}
$$

Rearranging (17) yields the sole haven deactivation condition (SHIC):

$$
\underbrace{(1+\lambda)\left[r h_{i}-b_{i}\right]}_{\text {shadow value * increase in net tax revenue }}-\underbrace{\frac{\beta}{\left(h_{1}+\beta\right)} r\left(h_{2}+\beta\right)}_{\text {decrease in net capital income }} \geq 0
$$

The condition (18) shows: for the deactivation of one tax haven to be profitable for $S$, the decrease in net capital income has to be compensated by 
an increase in net tax revenue. As $\frac{\beta}{\left(h_{1}+\beta\right)} r\left(h_{2}+\beta\right)$ and $\lambda$ is always positive, the level of compensation offered and paid to the deactivated haven plays an important role in this condition. The minimum possible compensation, which just compensates the tax haven for its loss in profits, as in Lemma 1 for $t=r$ can be inserted for $b_{i}$, which transforms (SHIC) into

$$
\begin{array}{cc}
-\frac{\beta}{\left(h_{1}+\beta\right)} r\left(h_{2}+\beta\right) \geq 0 & \text { when deactivating } H_{1} \\
\underbrace{(1+\lambda)\left[r h_{2}-\frac{h_{1}}{\left(h_{1}+\beta\right)} r\left(h_{2}+\beta\right)\right]}_{<0}-\frac{\beta}{\left(h_{1}+\beta\right)} r\left(h_{2}+\beta\right) \geq 0 & \text { when deactivating } H_{2}
\end{array}
$$

Thus, the condition SHIC is never fulfilled and $S$ will never deactivate only one tax haven.

Intuitively, there are several effects that can be distinguished. Consider, for instance, a deactivation of $H_{1}$. First, in the regime with only one tax haven active, all financial capital is charged at the same rate $r$. Compared to the default state with two active tax havens, capital owners lose $\frac{\beta}{\left(h_{1}+\beta\right)} r\left(h_{2}+\beta\right)$ in additional fees that are paid to tax havens. Taken in isolation, this constitutes a decrease in national welfare of $S$. Second, the deactivation of $H_{1}$ leads to an increase in total tax revenue for $S$ by $h_{1} r$ as more capital is immobile. Third, if the country $S$ chooses to deactivate $H_{1}$, it makes the smallest compensation offer that $H_{1}$ is willing to accept. This smallest offer is equal to $H_{1}$ 's payoff in the default state, which is equal to $h_{1} r$. The increase in tax receipts and the payment to $H_{1}$, hence, just cancel out. Overall, country $S$ just loses $\frac{\beta}{\left(h_{1}+\beta\right)} r\left(h_{2}+\beta\right)$ if it deactivates $H_{1}$. Further, should $S$ deactivate the smaller tax haven $H_{2}$ instead of $H_{1}$, this entails a further decrease in net tax revenue as the minimal compensation that the haven would be willing to accept is larger than the increase in total tax revenue. Condition (18) never holds. Therefore, there is no equilibrium outcome in which $S$ compensates only one haven, regardless of the size of $s$, $h_{1}$ and $h_{2}$.

\subsection{Deactivation of all tax havens}

The result in Proposition 4 reduces the problem to possible equilibria with deactivation of both, or none of the tax havens. We turn to this comparison now. Again, the problem is whether the compensations required are suffi- 
ciently low for making the deactivation of both tax havens attractive for $S$. We first derive a condition describing the maximum that $S$ is willing to pay.

Proposition 5 The country $S$ is better-off than in the default state if it deactivates both tax havens provided that the sum of compensations fulfills the condition

$$
b_{1}+b_{2}<r h_{1}+\left(\frac{h_{1}+\lambda\left(h_{1}+\beta\right)}{\left(h_{1}+\beta\right)(1+\lambda)}\right)\left(h_{2}+\beta\right) r .
$$

Proof. Country $S$ makes deactivation offers only if its payoff $\pi_{S}^{1,2}$ after deactivation is at least as high as its default payoff $\pi_{S}^{0}$. This condition can be written explicitly as

$$
\begin{aligned}
\pi_{S}^{1,2} & =1-r+(1+\lambda)\left[r-b_{1}-b_{2}\right] \\
& \geqslant 1-r s-h_{1} r+\frac{h_{1}}{\left(h_{1}+\beta\right)} r\left(h_{2}+\beta\right)+(1+\lambda) r s=\pi_{S}^{0}
\end{aligned}
$$

Rearranging yields:

$$
\underbrace{\frac{\beta}{\left(h_{1}+\beta\right)} r\left(h_{2}+\beta\right)}_{\text {decrease in net capital income }} \leq \underbrace{(1+\lambda)\left[r\left(h_{1}+h_{2}+\beta\right)-b_{1}-b_{2}\right]}_{\text {increase in net tax revenue }}
$$

This can be solved for $b_{1}$ and $b_{2}$ :

$$
b_{1}+b_{2} \leq r h_{1}+\frac{h_{1}}{\left(h_{1}+\beta\right)}\left(h_{2}+\beta\right) r+\frac{\lambda}{(1+\lambda)} \frac{\beta}{\left(h_{1}+\beta\right)}\left(h_{2}+\beta\right) r
$$

Intuitively, condition (21) demonstrates that, for the deactivation of both havens to be beneficial for $S$, the decrease in net capital income must be compensated by a sufficient increase in net tax revenue. If both tax havens are inactive, all capital is charged at the same rate $t=r$. By rearranging (20), a condition for the deactivation of both havens to be beneficial is derived. For this condition to hold, the offered bids cannot exceed a certain threshold. The sum of possible bids needs to be always higher than the sum of the havens' expected profits in the default scenario, which never exceeds $r\left(h_{1}+h_{2}+\beta\right)$. The upper bound for the sum of possible bids is a function of the shadow price of public funds. The higher $\lambda$, the nearer the possible bid level to $r\left(h_{1}+\right.$ $\left.h_{2}+\beta\right)$. This is intuitive, as an increase in $\lambda$ corresponds to a higher need for tax revenue, which then allows for higher bids to achieve the deactivation of the havens and thus eliminate the competition for mobile capital. 


\section{Deactivation equilibrium}

We have now shown that it is never an equilibrium for $S$ to deactivate just one tax haven. Further, Proposition 5 characterizes a maximum compensation that $S$ is willing to pay in order to deactivate both tax havens. The compensation that is needed in order to induce the two tax havens to close down is, however, a function of the deactivation regime. We show in this section that the compensation that would be needed in total to deactivate both tax havens exceeds the willingness of $S$ to pay in one of the two regimes: only with simultaneous joint offers may the deactivation of the tax havens be beneficial. Country $S$ can offer simultaneous joint offers or sequential offers. Subsequently we consider the two types of deactivation processes one after the other.

\subsection{Simultaneous joint offers}

First we consider a deactivation process in which $S$ makes a simultaneous joint offer $\left(b_{1}, b_{2}\right)$ to the two tax havens. The following result holds:

Proposition 6 If $S$ can make a simultaneous joint offer $\left(b_{1}, b_{2}\right)$, then a subgame perfect equilibrium exists in which both tax havens are deactivated, with payoffs

$$
\begin{gathered}
\pi_{1}^{1,2}=b_{1}=h_{1} r \\
\pi_{2}^{1,2}=b_{2}=\frac{h_{1}}{\left(h_{1}+\beta\right)} r\left(h_{2}+\beta\right)
\end{gathered}
$$

and

$$
\pi_{S}^{1,2}=1-r+(1+\lambda)\left(r s+\frac{\beta}{\left(h_{1}+\beta\right)} r\left(h_{2}+\beta\right)\right) .
$$

Proof. This regime's distinctive feature lies in the conditionality of the offers on the actions of the other haven, as each haven only receives a compensation when both accept the offers.

Suppose $S$ makes a simultaneous joint offer $\left(b_{1}, b_{2}\right)$. Figure 1 summarizes the payoffs for the four subgames, assuming equilibrium play in the respective subgames that are reached, depending on the decision of the havens to either accept or reject the offer of $S$. 


\begin{tabular}{|c|c|c|}
\hline \multirow{2}{*}{ Haven 1 } & \multicolumn{2}{|c|}{ Haven 2 } \\
\cline { 2 - 3 } & Accept & Reject \\
\hline Accept & $b_{1}, b_{2}$ & $h_{1} r, \frac{h_{1}}{h_{1}+\beta} r\left(h_{2}+\beta\right)$ \\
\hline Reject & $h_{1} r, \frac{h_{1}}{h_{1}+\beta} r\left(h_{2}+\beta\right)$ & $h_{1} r, \frac{h_{1}}{h_{1}+\beta} r\left(h_{2}+\beta\right)$ \\
\hline
\end{tabular}

Figure 1: Payoff matrix for the case of simultaneous joint offers

This uses $t=r$ and the expected profits stated in Lemma 1 for the competition phase subgame with both tax havens being active. In each of the four cases, the first entry corresponds to the payoff of $H_{1}$ and the second to the payoff of $H_{2}$. The tax havens receive $b_{1}$ and $b_{2}$, respectively, if both accept the offer, and they receive the payoffs of the default situation of two active havens if one or both of them reject the offer. Joint acceptance is, hence, an equilibrium choice if $b_{i} \geq E\left(\pi_{i}\right)$ for both $i=1,2$. Moreover, the smallest amounts $b_{1}$ and $b_{2}$ for which joint acceptances are optimal mutual replies by the tax havens are $b_{i}=E\left(\pi_{i}\right)$ for both $i=1,2$. These bids fulfill conditions (23) and (24) in Proposition 6 and, together with deactivation of both havens, yield (25). This payoff exceeds $\pi_{S}^{0}$ as in (6), as can be seen from comparing $E\left(\pi_{S}\right)$ in (6) and (25). (The comparison boils down to $\frac{\left(\beta+\lambda \beta+h_{1}\right)}{\left(h_{1}+\beta\right)}>1$, which is true. $)$

Proposition 6 is one of the main results in this paper. It shows that $S$ can profitably deactivate all tax havens, provided that it can make a simultaneous joint offer to all tax havens. We will later compare this offer regime with the sequential offer regime and find that the simultaneous joint offer regime is the only regime that allows for a deactivation of tax havens that is beneficial for $S$.

Intuitively, if $S$ can make a simultaneous joint offer, the tax havens understand that they will never become the only active tax haven. Either both give up their tax haven business, or both stay active. Accordingly, it is optimal for them if they both accept the offer provided that the offer is at least as attractive for them as the default situation, but they should reject any lower offer. Moreover, if country $S$ anticipates this behavior, it will not make an offer that exceeds the smallest offer which both tax havens are willing to accept.

Note that the equilibrium in Proposition 6 is not unique, due to the coordination problem between the two tax havens. The simultaneous joint offers lead to payments and deactivation of both tax havens only if both tax havens accept the offer. Consider, for instance, offers $\left(b_{1}, b_{2}\right)$ with $b_{1}>h_{1} r$ and $b_{2}>\frac{h_{1}}{h_{1}+\beta} r\left(h_{2}+\beta\right)$. Although it would be beneficial for $H_{1}$ and $H_{2}$ to 
accept the offers, there is also an equilibrium in which both reject the offers. If tax haven $H_{1}$ expects $H_{2}$ to reject the offer (for whatever reason), then $H_{1}$ is indifferent regarding whether to accept or reject the offer, because both choices lead to the same outcome (see Figure 1). The same logic applies for $\mathrm{H}_{2}$, rationalizing $\mathrm{H}_{2}$ 's choice to reject the offer. Hence, rejecting the offers constitute mutually optimal replies.

Note further that this multiplicity of equilibrium outcomes could be used by the tax havens to leverage up their equilibrium payoffs. For instance, if $S$ expects the tax havens to end up in this rejection equilibrium for all offers $\left(b_{1}, b_{2}\right)$ with $b_{1}<h_{1} r+\Delta$ and $b_{2}<\frac{h_{1}}{h_{1}+\beta} r\left(h_{2}+\beta\right)+\Delta$, but with both accepting the offers for $b_{1} \geq h_{1} r+\Delta$ and $b_{2} \geq \frac{h_{1}}{h_{1}+\beta} r\left(h_{2}+\beta\right)+\Delta$, this can support equilibria in which country $S$ has to pay an additional $2 \Delta$ compared to the minimum offers that are accepted in the equilibrium in Proposition 6 .

These equilibria, which are based on coordination failure are, however, not robust. They rely on $H_{i}$ being indifferent regarding whether to accept or to reject if $H_{i}$ thinks that $H_{j}$ will reject. Country $S$ can break this indifference if it can offer a menu that offers $H_{i}$ also a very small payment for the case in which $H_{i}$ accepts but $H_{j}$ rejects the offer.

\subsection{Independent sequential offers}

Rather than a once-and-for-all simultaneous joint offer, what the OECD pursues with its Harmful Tax Practices Initiative is a more sequential process in which bilateral information exchange agreements are sequentially negotiated and signed between tax havens and non-tax-haven countries. Consider therefore the sequential deactivation regime, where $S$ first approaches one haven $H_{i}$ with a bid $b_{i}$ for deactivation and then can make a bid $b_{j}$ to the other tax haven $H_{j}$, where it can adjust this bid taking into consideration whether the previous bid to $H_{i}$ was accepted or not.

Proposition 7 If S can make sequential independent offers, the sum of compensations needed to deactivate both tax havens is smaller if the tax haven with more loyal capital (with higher $h_{i}$ ) is compensated first. Overall, the combination of $\left(b_{i}, b_{j}().\right)$ that would make both havens accept the offers exceeds country $S$ 's willingness to pay.

Proof. Using backward induction, we derive the subgame perfect equilibrium of this offer regime. Assume that $S$ first makes an offer $b_{i}$ to $H_{i}$, and then, depending on the outcome, possibly an offer $b_{j}($.$) to H_{j}$. 
Note that no offer $b_{j}$ is made if $b_{i}$ was not accepted, as this would lead to the deactivation of one tax haven only, and it was shown in Proposition 4 that it is not profitable for $S$ to deactivate only one tax haven. Suppose therefore that $H_{i}$ has accepted the offer $b_{i}$, and consider the behavior of $H_{j}$ for a given $b_{j}($.$) , given that H_{i}$ is deactivated. Given that $H_{j}$ is the only tax haven that is possibly active, the offer is acceptable for $H_{j}$ if and only if $b_{j}(.) \geq\left(h_{j}+\beta\right) r$. If $S$ makes such an offer, it chooses the smallest acceptable offer, $b_{j}()=.\left(h_{j}+\beta\right) r$.

Turn now to the compensation offer $b_{i}$. As a consequence of Proposition 4, $H_{i}$ anticipates that $S$ will never offer a deactivation bid to $H_{j}$ if $H_{i}$ rejects the offer $b_{i}$. Thus, the optimal strategy of $H_{i}$ is:

$$
\begin{aligned}
& \text { Reject if } b_{i}<\pi_{i}^{0} \\
& \text { Accept if } b_{i} \geq \pi_{i}^{0}
\end{aligned}
$$

Accordingly, $S$ will either make a bid $b_{i}=\pi_{i}^{0}$ or no bid at all.

The lowest feasible sum of bids that deactivates both tax havens, hence, is

$$
b_{i}+b_{j}(.)=\pi_{i}^{0}+\pi_{j}^{i} .
$$

Country $S$ makes these sequential offers if the sum of these offers fulfills inequality (19) in Proposition 5.

Before we check whether (19) can be fulfilled for successful sequential offers, note that $\pi_{1}^{0}+\pi_{2}^{1} \leq \pi_{2}^{0}+\pi_{1}^{2}$. This can be seen by inserting $\pi_{2}^{1}=$ $\left(h_{2} r+\beta r\right), \pi_{1}^{2}=\left(h_{1} r+\beta r\right)$ and $\pi_{1}^{0}$ and $\pi_{2}^{0}$ for $t=r$ as in Lemma 1 into this inequality, which becomes equivalent to the condition $h_{1} \geq h_{2}$. Accordingly, if $S$ makes an offer, the first offer is made to tax haven $H_{1}$.

Using the condition (19) from Proposition 5, $S$ makes an offer if

$$
h_{1} r+h_{2} r+\beta r \leq r h_{1}+\left(\frac{h_{1}+\lambda\left(h_{1}+\beta\right)}{\left(h_{1}+\beta\right)(1+\lambda)}\right)\left(h_{2}+\beta\right) r
$$

or, equivalently,

$$
1 \leq 1-\frac{\beta}{\left(h_{1}+\beta\right)(1+\lambda)},
$$

and this condition can never be fulfilled for $\beta>0$.

The deactivation of both tax havens is expensive. Intuitively, the sequential procedure has a major drawback: once the first tax haven has been 
deactivated, this considerably benefits the tax haven that remains. This remaining tax haven makes a much larger profit than in the default regime in which the tax havens compete, since it has lost its main competitor. Country $S$ therefore has to pay a very high price for deactivating the remaining tax haven monopoly. This competition effect of the sequential nature of the squeeze-out is one of the key results of the paper. It provides a potentially important lesson for the ongoing process by which the OECD tries to close down one tax haven after another. While the closing down of single tax havens is not very expensive initially, compensating further tax havens to close down their operation becomes increasingly costly: due to the reduced competition, the tax havens' business becomes more profitable, and this increases the compensation needed.

If -for whatever reason- the OECD initiative has to follow a sequential path, Proposition 7 highlights an important second-best result: it is superior to start this sequential process by making an offer to the strongest tax haven(s) first (i.e., the one with the largest $h_{i}$ ) and then move on to the smaller tax havens later. This is also not necessarily in line with observed behavior in the Harmful Tax Practices Initiative.

\subsection{Comparing offer regimes}

We can also compare the equilibrium outcomes for the two offer regimes.

Proposition 8 Comparing the least-cost offers in the two offer regimes by which $S$ can deactivate all tax havens, the least-cost simultaneous joint offer is less cost for $S$ than the least-costly sequential independent offers.

The result in Proposition 8 follows directly from a comparison of Propositions 6 and 7: the necessary deactivation payments in the sequential offers regime exceed the benefits of deactivation, but the payments in the simultaneous joint offer regime do not. Hence, the sum of compensations is lower in the simultaneous joint offer regime than in the sequential regime.

Intuitively, in the case of simultaneous joint offers, none of the tax havens can hope to become the only active tax haven in the competition phase. When deciding about staying active, they compare the compensation offered to their payoff in a situation in which they compete with other tax havens. In the sequential regime, the possibility of becoming a monopoly tax haven plays an important role. The second tax haven that is approached is the 
monopoly tax haven in this case. Therefore, considerably more must be offered to this tax haven to make it attractive to become inactive.

To illustrate the potential magnitude of the effect, consider, for instance, $h_{1}=h_{2}=0$. In this case, if both tax havens are active, they earn zero payoffs, as all existing capital perceives the two havens as perfect substitutes in a Bertrand game. In the equilibrium in Proposition 6 , the country $S$ can close down both tax havens by making joint simultaneous offers that sum up to $b_{1}+b_{2}=0+0=0$. In the sequential game, the equilibrium payment offers are $b_{i}+b_{j}()=.0+r \beta$.

\section{Conclusions}

This paper considers the problem of how to deactivate tax havens in a world with multiple tax havens. The fight against tax havens has many aspects that we did not address here. For instance, we disregarded the problem of coordinated action among the non-tax-haven countries, and rather considered one big non-haven country or player such as the OECD, that is able to internalize the benefits and cost of a deactivation initiative such as the Harmful Tax Practices Initiative.

Our analysis highlights an important issue that is largely neglected in the current fight against tax havens: Once this fight shows some initial success, that is, once some of the tax havens have successfully been approached and convinced to close down their operations, this will change the nature of competition among the tax havens that remain active. Competition between these tax havens will relax, due to the exit of some of their competitors. The rents they earn from their "services" to financial capital, and other tax haven "services" more generally, increase as the number of tax havens is reduced.

This effect has a number of relevant implications.

First, it reveals that a sequential fight against tax havens is easier in its initial phase. The initial series of successes in the fight against tax havens clouds the size of the true problem. It should not make us confident as regards the likelihood of final success. The more tax havens have been closed down, the harder it will be to convince the remaining tax havens to give up their tax haven business. It may actually become excessively expensive to close down the last few tax havens, as these tax havens will earn very high monopoly rents.

Second, closing down just a few tax havens leads to a situation that is 
potentially worse (from a welfare point of view of the OECD countries) than a situation with a large number of tax havens. If many tax havens offer their services and compete for capital, their fees will be low. Tax revenues will also be low, but at least the capital (and its returns) remains with its owners in the OECD countries. If a major share of tax havens have been closed down and only a limited number of tax havens are still active, competition between them will be reduced. Hence, fees for tax-sheltering services are high in the equilibrium outcome. Tax revenue in OECD countries may still be low, but a large share of the returns of capital is taken away from its owners and transferred to the tax havens (as fees).

Third, the analysis suggests that, if it comes to fighting tax havens, a coordinated and conditional "big-bang" policy initiative which tries to form a simultaneous multilateral agreement between all non-tax-haven countries and all tax-havens is superior (less expensive) compared to a sequential process of closing down one tax haven after another.

Fourth, if a "big-bang" policy is not feasible and only a sequential policy is possible, then the order matters for the cost of a sequential policy. Our analysis suggests that a sequential policy should address those tax havens first which are already particularly successful in the initial situation with competition between tax havens.

\section{References}

Andersson, F. and K. Konrad (2001). Globalization and human capital formation. IZA Discussion Papers 245.

Bagwell, K. and R. W. Staiger (2004). Multilateral trade negotiations, bilateral opportunism and the rules of GATT/WTO. Journal of International Economics 63(1), 1-29.

Chisik, R. and R. B. Davies (2004). Asymmetric FDI and tax-treaty bargaining: theory and evidence. Journal of Public Economics 88(6), 1119 $-1148$.

Desai, M. A., C. F. Foley, and J. J. Hines (2006). Do tax havens divert economic activity? Economics Letters 90(2), 219-224.

Dharmapala, D. (2008). What problems and opportunities are created by tax havens? Oxford Review of Economic Policy 24(4), 661-679. 
Dixit, A. (1984, Supplemen). International trade policy for oligopolistic industries. Economic Journal 94(376a), 1-16.

Hong, Q. and M. Smart (2010). In praise of tax havens: International tax planning and foreign direct investment. European Economic Review $54(1), 82-95$.

Horn, H. and J. Levinsohn (2001). Merger policies and trade liberalisation. Economic Journal 111(470), 244-76.

Horn, H. and L. Persson (2001). Endogenous mergers in concentrated markets. International Journal of Industrial Organization 19(8), 12131244 .

Johannesen, N. (2010). Imperfect tax competition for profits, asymmetric equilibrium and beneficial tax havens. Journal of International Economics $81(2)$, 253-264.

Konrad, K. A. and D. Kovenock (2009). Competition for FDI with vintage investment and agglomeration advantages. Journal of International Economics 79(2), 230-237.

Kudrle, R. T. (2008). The OECD's Harmful Tax Competition Initiative and the tax havens: From bombshell to damp squib. Global Economy Journal 8(1), 1-23.

Lommerud, K. E., O. R. Straume, and L. Sorgard (2006). National versus international mergers in unionized oligopoly. RAND Journal of Economics $37(1), 212-233$.

Marceau, N., S. Mongrain, and J. D. Wilson (2010). Why do most countries set high tax rates on capital? Journal of International Economics 80(2), 249-259.

Narasimhan, C. (1988). Competitive promotional strategies. The Journal of Business 61(4), 427-449.

Norbäck, P.-J., L. Persson, and J. Vlachos (2009). Cross-border acquisitions and taxes: efficiency and tax revenues. Canadian Journal of Economics 42(4), 1473-1500.

OECD (1998). Harmful Tax Competition: An Emerging Global Issue. OECD Publishing. 
Slemrod, J. (2008). Why is Elvis on Burkina Faso postage stamps? crosscountry evidence on the commercialization of state sovereignty. Journal of Empirical Legal Studies 5 (4), 683-712.

Slemrod, J. and J. D. Wilson (2009). Tax competition with parasitic tax havens. Journal of Public Economics 93(11-12), 1261-1270.

Torvik, R. (2009). Why are tax havens more harmful to developing countries than to other countries? Report from the Government Commission on Capital Flight from Poor Countries, 155 - 194.

Varian, H. R. (1980). A model of sales. American Economic Review 70(4), $651-59$.

Wang, X. (2004). Tax evasion, tax competition and gains from nondiscrimination with equilibrium mixed strategies. Economics Letters 83(3), $377-381$. 


\section{CESifo Working Paper Series}

for full list see www.cesifo-group.org/wp

(address: Poschingerstr. 5, 81679 Munich, Germany, office@cesifo.de)

3132 John Komlos and Marek Brabec, The Trend of BMI Values by Centiles of US Adults, Birth Cohorts 1882-1986, July 2010

3133 Emin Karagözoğlu and Arno Riedl, Information, Uncertainty, and Subjective Entitlements in Bargaining, July 2010

3134 John Boyd, Gianni De Nicolò and Elena Loukoianova, Banking Crises and Crisis Dating: Theory and Evidence, July 2010

3135 Michael R. Baye, Dan Kovenock and Casper G. de Vries, The Herodotus Paradox, July 2010

3136 Martin Kolmar and Hendrik Rommeswinkel, Group Contests with Complementarities in Efforts, July 2010

3137 Carolina Manzano and Xavier Vives, Public and Private Learning from Prices, Strategic Substitutability and Complementarity, and Equilibrium Multiplicity, July 2010

3138 Axel Löffler, Gunther Schnabl and Franziska Schobert, Inflation Targeting by Debtor Central Banks in Emerging Market Economies, July 2010

3139 Yu-Fu Chen and Michael Funke, Global Warming and Extreme Events: Rethinking the Timing and Intensity of Environmental Policy, July 2010

3140 Lawrence M. Kahn, Labor Market Policy: A Comparative View on the Costs and Benefits of Labor Market Flexibility, July 2010

3141 Ben J. Heijdra, Jochen O. Mierau and Laurie S.M. Reijnders, The Tragedy of Annuitization, July 2010

3142 Erkki Koskela, Outsourcing Cost and Tax Progression under Nash Wage Bargaining with Flexible Outsourcing, July 2010

3143 Daniel Osberghaus and Christiane Reif, Total Costs and Budgetary Effects of Adaptation to Climate Change: An Assessment for the European Union, August 2010

3144 Philip E. Graves, Benefit-Cost Analysis of Environmental Projects: A Plethora of Systematic Biases, August 2010

3145 Sabrina Di Addario and Daniela Vuri, Entrepreneurship and Market Size. The Case of Young College Graduates in Italy, August 2010

3146 Shoshana Amyra Grossbard and Alfredo Marvăo Pereira, Will Women Save more than Men? A Theoretical Model of Savings and Marriage, August 2010 
3147 Jarko Fidrmuc, Time-Varying Exchange Rate Basket in China from 2005 to 2009, August 2010

3148 Ilja Neustadt and Peter Zweifel, Is the Welfare State Sustainable? Experimental Evidence on Citizens' Preferences for Redistribution, August 2010

3149 Marcus Dittrich and Andreas Knabe, Wage and Employment Effects of Non-Binding Minimum Wages, August 2010

3150 Shutao Cao, Enchuan Shao and Pedro Silos, Fixed-Term and Permanent Employment Contracts: Theory and Evidence, August 2010

3151 Ludger Woessmann, Cross-Country Evidence on Teacher Performance Pay, August 2010

3152 Lorenzo C. G. Pozzi, Casper G. de Vries and Jorn Zenhorst, World Equity Premium Based Risk Aversion Estimates, August 2010

3153 Volker Grossmann, Thomas M. Steger and Timo Trimborn, Dynamically Optimal R\&D Subsidization, August 2010

3154 Alexander Haupt, Tim Krieger and Thomas Lange, A Note on Brain Gain and Brain Drain: Permanent Migration and Education Policy, August 2010

3155 António Afonso and Christophe Rault, Long-run Determinants of Sovereign Yields, August 2010

3156 Franziska Tausch, Jan Potters and Arno Riedl, Preferences for Redistribution and Pensions. What can we Learn from Experiments?, August 2010

3157 Martin Kolmar and Andreas Wagener, Inefficient Group Organization as Optimal Adaption to Dominant Environments, August 2010

3158 Kai Carstensen, Klaus Wohlrabe and Christina Ziegler, Predictive Ability of Business Cycle Indicators under Test: A Case Study for the Euro Area Industrial Production, August 2010

3159 Horst Rottmann and Timo Wollmershäuser, A Micro Data Approach to the Identification of Credit Crunches, August 2010

3160 Philip E. Graves, Appropriate Fiscal Policy over the Business Cycle: Proper Stimulus Policies Can Work, August 2010

3161 Michael Binder and Marcel Bluhm, On the Conditional Effects of IMF Program Participation on Output Growth, August 2010

3162 Michael Binder, Qianying Chen, and Xuan Zhang, On the Effects of Monetary Policy Shocks on Exchange Rates, August 2010

3163 Felix J. Bierbrauer, On the Optimality of Optimal Income Taxation, August 2010 
3164 Nikolaus Wolf, Europe's Great Depression - Coordination Failure after the First World War, September 2010

3165 Dan Kovenock and Brian Roberson, Conflicts with Multiple Battlefields, September 2010

3166 Jean-Pierre Ponssard and Catherine Thomas, Capacity Investment under Demand Uncertainty. An Empirical Study of the US Cement Industry, 1994-2006, September 2010

3167 Jørgen Juel Andersen, Jon H. Fiva and Gisle James Natvik, Voting when the Stakes are High, September 2010

3168 Michael Hoel, Is there a Green Paradox?, September 2010

3169 Scott Alan Carson, Nineteenth Century US African-American and White Female Statures: Insight from US Prison Records, September 2010

3170 Gil S. Epstein, Yosef Mealem and Shmuel Nitzan, Political Culture and Discrimination in Contests, September 2010

3171 Sara Fisher Ellison, Jeffrey Greenbaum and Wallace P. Mullin, Diversity, Social Goods Provision, and Performance in the Firm, September 2010

3172 Silvia Dominguez-Martinez, Randolph Sloof and Ferdinand von Siemens, Monitoring your Friends, not your Foes: Strategic Ignorance and the Delegation of Real Authority, September 2010

3173 Marcus Dittrich and Beate Schirwitz, Union Membership and Employment Dynamics: A Note, September 2010

3174 Francesco Daveri, Paolo Manasse and Danila Serra, The Twin Effects of Globalization - Evidence from a Sample of Indian Manufacturing Firms, September 2010

3175 Florian Blöchl, Fabian J. Theis, Fernando Vega-Redondo and Eric O’N. Fisher, Which Sectors of a Modern Economy are most Central?, September 2010

3176 Dag Morten Dalen, Marilena Locatelli and Steinar Strøm, Longitudinal Analysis of Generic Substitution, September 2010

3177 Armin Falk, Stephan Meier and Christian Zehnder, Did we Overestimate the Role of Social Preferences? The Case of Self-Selected Student Samples, September 2010

3178 Christian Fahrholz and Cezary Wójcik, The Bail-Out! Positive Political Economics of Greek-type Crises in the EMU, September 2010

3179 Klaus Abberger and Wolfgang Nierhaus, The Ifo Business Cycle Clock: Circular Correlation with the Real GDP, September 2010 
3180 Walter Krämer and Gerhard Arminger, "True Believers" or Numerical Terrorism at the Nuclear Power Plant, September 2010

3181 Bernard M.S. Van Praag, Dmitri Romanov and Ada Ferrer-i-Carbonell, Happiness and Financial Satisfaction in Israel. Effects of Religiosity, Ethnicity, and War, September 2010

3182 Dimitrios Koumparoulis and Paul De Grauwe, Public Capital, Employment and Productivity: An Empirical Investigation for Greece, September 2010

3183 John Whalley and Tanmaya Shekhar, The Rapidly Deepening India-China Economic Relationship, September 2010

3184 Andreas Schäfer and Thomas Steger, History, Expectations, and Public Policy: Economic Development in Eastern Germany, September 2010

3185 Thomas Eichner and Marco Runkel, Subsidizing Renewable Energy under Capital Mobility, September 2010

3186 Konstantinos Angelopoulos and James Malley, Fear of Model Misspecification and the Robustness Premium, September 2010

3187 Philip E. Graves, A Note on the Design of Experiments Involving Public Goods, September 2010

3188 Glenn Ellison, How does the Market Use Citation Data? The Hirsch Index in Economics, September 2010

3189 Barbara Hanel and Regina T. Riphahn, The Employment of Mothers - Recent Developments and their Determinants in East and West Germany, September 2010

3190 Alexander Haupt and Silke Uebelmesser, Integration, Mobility, and Human Capital Formation, September 2010

3191 Vincenzo Galasso and Paola Profeta, When the State Mirrors the Family: The Design of Pension Systems, September 2010

3192 Stéphane Zuber and Geir B. Asheim, Justifying Social Discounting: The RankDiscounted Utilitarian Approach, September 2010

3193 Alexander Kemnitz, Educational Federalism and the Quality Effects of Tuition Fees, September 2010

3194 Claudia M. Buch, Sandra Eickmeier and Esteban Prieto, Macroeconomic Factors and Micro-Level Bank Risk, September 2010

3195 May Elsayyad and Kai A. Konrad, Fighting Multiple Tax Havens, September 2010 